\title{
Observability and Sorting in a Market for Names*
}

\author{
Joyee $\operatorname{Deb}^{\dagger}$
}

August, 2007

\begin{abstract}
Can firm names be tradeable assets when changes in name ownership are observable? Earlier literature suggests that non-observability is critical to sustaining name trading. Yet, casual empiricism suggests that shifts in name ownership may be publicly known. This paper shows how firm names can be traded even under full observability. In equilibrium, even when consumers see a reputed name being divested they continue trusting it and so, these names are tradeable. I also demonstrate an appealing "sorting" property of the equilibria. Competent firms separate themselves by buying valuable names, or incompetent firms give themselves away by using worthless names.
\end{abstract}

${ }^{*}$ I am indebted to Johannes Hörner for his dedicated mentoring and encouragement. I would like to thank Sourav Bhattacharya, Jeff Ely, Péter Eső, Ehud Kalai, Peter Klibanoff and Tapas Kundu for helpful comments.

${ }^{\dagger}$ Managerial Economics and Decision Sciences, Kellogg School of Management, Northwestern University; j-deb@kellogg.northwestern.edu 


\section{Introduction}

While describing the recent acquisition of IBM's ThinkPad name by computer manufacturer Lenovo, the New York Times wrote: ${ }^{1}$

When Lenovo, the Chinese personal computer maker, bought I.B.M.'s personal computing business for USD 1.75 billion in December 2004... Lenovo executives assumed rightly that the I.B.M. brand would still resonate in the United States market and serve to assuage the worries of existing and prospective customers about the I.B.M. ThinkPad line of laptops. Lenovo also realized there would be concern among American customers about buying from a China-based company they had never heard of.

This situation highlights two important phenomena related to firm reputations.

First, firms may publicly buy and sell their names like other valuable tradeable assets. As in the case of Lenovo and ThinkPad, the sale of a well-established name may be public because it is covered widely by the business press. Changes of firm ownership may be publicly known because disclosure is mandated by law. Even when not mandated by law, we see that a new owner may choose to make it known - haven't we seen local restaurants announce "Under New Management"?

Second, the market for firm names can exhibit a sorting property, in the sense that wellestablished names are usually bought by good firms. Consider the example of 'Waterman' a famous premium brand of pens which changed ownership multiple times. Each time the brand was sold, it was bought by a well-established firm, once by Gillette in 1992 and more recently by Rubbermaid. IBM was bought by Lenovo the largest PC manufacturer in China. When Nabisco sold its well-known 'Shredded Wheat' cereal brand, the potential buyers were trusted companies, Kraft and General Mills. In fact it must be such a sorting property that enables consumers to trust a name even after they know it has been sold. In the Lenovo example, even after the ThinkPad name was sold, it appears that consumers continued to trust and buy it. They must have believed that a firm capable of buying a name such as ThinkPad was likely to be "good", and would continue to

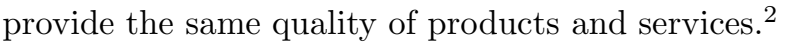

The existing theory on firm reputations does not explain either of these two phenomena. On the contrary, the standard models (e.g. Kreps 1990, Tadelis 1999) have two opposite features. First, non-observability of name trading is a key assumption. The main result in this literature

\footnotetext{
${ }^{1}$ See "Quickly Erasing I and B and M" by Glenn Rifkin \& Jenna Smith, New York Times, April 12, 2006

${ }^{2}$ See "Brands Still Easier to Buy than Create" by Kenneth N. Gilpin, New York Times, September 14, 1992.
} 
is that names are traded in all equilibria, but this result relies critically on the non-observability assumption which is the source of value for names. Consumers believe that the current owner is responsible for the good name or record of the firm, and good past record generates expectation of good future performance. Good names become tradeable because a firm can secretly buy a good name and create expectation of good performance and earn higher revenues.

The second feature of current models is the absence of sorting equilibria. A key result is that the trading equilibria are all pooling equilibria. It is not possible for good firms to separate themselves from the bad firms by buying valuable names. There are always some bad firms using valuable names in equilibrium.

This brings us to the two main questions addressed in this paper. First, can we do away with the assumption of non-observability and develop a theory to explain why firm names are valuable even when clients can observe changes in name ownership? Second, under what conditions and how can the market for firm names separate good firms from bad ones?

I consider an infinite horizon economy with generations of firms and consumers interacting in each period. Both firms and consumers live for only one period. Consumers are homogeneous and are on the long side of the market. Firms are of two types - competent and incompetent. Competent firms can choose to work hard or be lazy. Working hard is costly but likely to result in good quality products or services. Laziness always results in bad quality. Incompetent firms are always lazy and so incapable of producing good quality. Consumers buy a product or service from the firm for which they pay upfront. At the time of purchase, consumers do not see the type of the firm or the quality of the product. They only see the name of the firm, and must pay a wage based on the name.

Firms choose to appear in the market under different names which they buy in a competitive market for names. The basic intuition of the model can be understood using two types of names. So, for most part of the paper, I focus on this case. Firms can choose to enter with new names $(N)$ or successful names $(S)$. Entering with an $N$-name is cheaper than entering with an $S$-name. After collecting the wages, competent firms can choose to work hard or be lazy. At the end of the period, each firm's reputation or name ${ }^{3}$ changes based on the quality of products it has provided. Names evolve according to a fixed transition rule (potentially random) which specifies a firm's reputation at the end of the period, based on its original reputation and the quality of products provided. Before retiring, a firm can sell its reputation to a new entrant.

\footnotetext{
${ }^{3}$ For the rest of the paper, I use "firm reputation" and "firm name" interchangeably.
} 
In this environment, the existence of a market for names affects incentives of firms in two ways. First, it influences the effort choice of the firm. The continuation payoff from selling a valuable name can make firms work hard to produce good quality. Also, the market may give firms incentives to buy one name rather than another one. For instance, a firm may choose to buy a costly name because consumers pay higher wages for it, or because a costly name is more likely to remain good and gives a higher continuation payoff.

It is worth noting here why this setting is particularly well-suited to analyze the value of firm names when name trading is observable. In a departure from the literature which always considers overlapping generations of firms, I consider a model where firms and consumers are all short-lived. Therefore it is common knowledge that name ownership changes every period. When a consumer meets a firm, she knows that the firm bought its name before entering.

With full observability of name changes, I examine the existence of equilibria in which the market for names both causes competent firms to work hard and sorts firms according to their type. I define a class of equilibria called sorting high-effort equilibria (SHE) where at least one type of firm has a strict incentive to not use one of the two names, and competent firms always work hard. In the main result of the paper, I characterize necessary and sufficient conditions for the existence of such sorting high-effort equilibria (SHE). I show that SHE exist provided the cost of effort is low enough for competent firms.

Two kinds of sorting arise in equilibrium. It is possible for competent firms to separate themselves by being the only ones buying the valuable successful names. I call these situations "Trust $S$-Names equilibria". In these equilibria, when consumers see a successful name, they trust it to be a competent firm and pay the corresponding high price. The higher wages for an $S$-name provide firms incentives to buy these names. Higher continuation payoffs from an $S$ reputation - provided the same reputation is maintained - give competent firms the incentive to work hard, and guarantee that incompetent firms do not find it worthwhile to buy these names. Note that there is effort exertion by competent firms in equilibrium even though they are sorted out from the incompetent firms. In other words, here, unlike in earlier models, moral hazard suffices to provide incentives to exert effort, even in the absence of adverse selection.

The second type of sorting that arises is termed "Mistrust $N$-Names". Here, incompetent firms give themselves away by being the only firms using the cheap names. Consumers treat cheap names with mistrust and pay them corresponding low wages. Competent firms force this situation to arise by always buying $S$-names before entering the market. Note that both types of sorting allow firms 
to still pool on one name. In "Trust $S$-Names equilibria", $S$-names separate competent firms from incompetent ones. But some competent firms may still pool with incompetent firms on $N$-names. Similarly, in "Mistrust $N$-Names" equilibria, firms separate with $N$-names but may pool on $S$ names. In fact it will be shown that, generically, pooling on one name is required for the existence of high-effort equilibria in this model.

The type of sorting high-effort equilibria that arises depends on the transition rule posited. I show that for deterministic transition rules, the only type of sorting sustainable in a market with two names is the "Mistrust $N$-Names" type. Equilibria with deterministic rules have the appealing feature that they remain equilibria even in richer information structures, for instance when consumers observe not just a name but the full history of outcomes of a particular name. With random transition rules, both types of sorting can arise in equilibrium, as long as the cost of hard work is low enough. I characterize the transition rules that give rise to each of the two types of sorting. ${ }^{4}$

I examine the relationship between observability and separation. It turns out that under observability, the requirement for separation in equilibrium is not a restrictive one. Relaxing the requirement for sorting does not extend the range of parameter values under which high-effort equilibria exist.

Finally in an extension of the model, I study the welfare implications of observability of name trades. Since I restrict attention to high-effort equilibria, the total surplus of firms and consumers is constant across regimes. However, observability does affect consumer and firm surplus. I present examples where observability is irrelevant, observability makes consumers better off and worse off.

The rest of the paper is structured as follows: Section 2 describes the basic model. Section 3 presents two simple examples where firm ownership changes are observable and sorting high-effort equilibria exist. In Section 4, I consider a market with more general transition rules and characterize the necessary and sufficient conditions under which sorting high-effort equilibria exist. Section 5 presents an extension which allows us to compare regimes with and without observability. Section 6 discusses the relationship between the results in this paper and those in related literature. Section 7 concludes. Proofs of most results are in the appendix.

\footnotetext{
${ }^{4}$ Sorting high-effort equilibria that arise with random transition rules are perhaps less appealing because they fail to remain equilibria if consumers actually observed the full history of outcomes of a firm name. However, I conjecture that a two-state market with random transitions may be equivalently represented by a richer market with more states and deterministic transitions.
} 


\section{The Basic Model}

There is a continuum of firms of unit measure. Firms live for one period only. In each period, they meet clients who are also short-lived. Consumers are homogeneous and are on the long side of the market. The following stage game is played by firms and consumers each period. Assume that the same play has occurred forever into the past. At the beginning of each period, the firm enters the market. At the time of entry, it has to choose a name for itself. After entry, the firm meets one client who pays it an upfront wage for its service. All a client sees at the time of purchase is the name of that particular firm. So, the wage paid depends only on the observed name. After collecting its wage, the firm makes an action choice. It has two choices: work hard $(H)$ or be lazy $(L)$. Being lazy is costless while working hard involves a cost $c>0$. There are two possible outcomes that can arise from the action chosen - good $(G)$ or bad $(B)$. The probability of a good outcome given hard work is $(1-\rho)$ with $\rho \in(0,1)$. If the firm is lazy, a bad outcome occurs with probability 1 . Firms are of two types, competent $(C)$ or incompetent $(I)$. A proportion $\phi \in(0,1)$ is competent. A competent firm can choose to work hard or be lazy. An incompetent firm is incapable of working hard. After the firm takes its action, the outcome occurs, and the firm's name changes based on a pre-determined transition rule. The firm can sell its (changed) name before retiring. Figure 1 describes the sequence of events in a period.

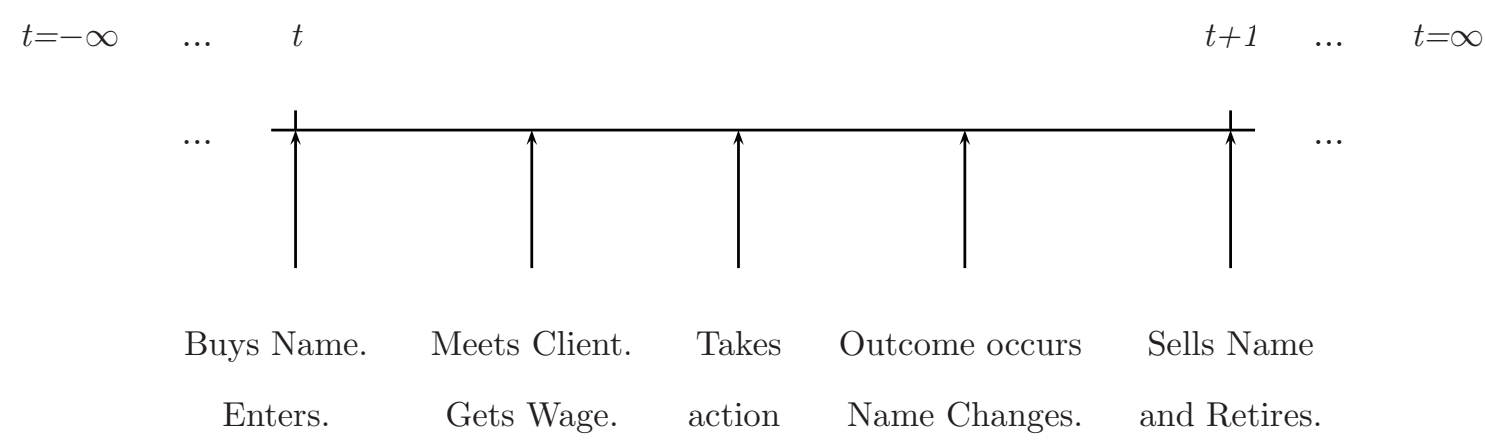

Figure 1: Timing of Events within a Period

\subsection{The Market for Firm Names}

In the market for firm names, there are two kinds of names, $S$ and $N$. By convention, I call the cheaper name $N$ and the more expensive name $S$. The market for names is competitive and names trade at prices $V_{S}$ and $V_{N}$ respectively. An entrant can buy (and an exiting firm can sell) a name of 
its choice from a retiring firm (to an entrant) at these prices. Without loss of generality, normalize the price of the cheaper name $V_{N}$ to 0 . I also assume that there is no shortage of the cheaper name. Think of entering with an $N$-name to be equivalent to entering with no reputation at all. The market is characterized by a transition rule. Define a non-random transition rule as follows.

Definition 1 A non-random transition rule is a function $f:\{S, N\} \times\{G, B\} \rightarrow\{S, N\}$.

A transition rule can be thought of as a device that describes how a name evolves based on the performance of its owner. As mentioned earlier, at the end of the period, the firm sells its (now changed) name if possible, to a new entrant and then retires. In a later section, I generalize the analysis by allowing random transitions rules, which specify not a deterministic transition but a distribution over future names based on the original name and the outcome.

The market for names affects the incentives of firms in two ways. First, it influences the effort choice of the competent type. The expected continuation payoff from selling a valuable name can make competent firms exert effort, even though they are short-lived. Second, the market may give firms incentives to buy one name rather than another. For instance, a firm may choose to buy a costly 'good' name because consumers pay higher wages for 'good' names, or because the transition rule is such that a 'good' name gives a higher continuation payoff.

Notice that changes in name ownership are trivially observable in this setting. When consumers see a name, they know that the firm bought this name at the time of entry.

\subsection{Payoffs}

Firms have a discount factor of $\delta$. The net payoff to a firm consists of the wages it receives plus the discounted proceeds from selling its name less the price it pays to buy its name, less the cost of effort. Clients get utility 0 from a bad outcome and utility 1 from a good one. Since clients can observe only the firm name and cannot observe the outcome at the time of payment, they pay firms wages equal to their expected utility conditional on the observed name, given the firms' strategies. Denote the wages conditional on the name by $w_{S}$ and $w_{N}$. Since clients make no real decision in the game, they are not explicitly modeled as players in what follows.

\subsection{Definition of Equilibrium}

In this paper, we consider simple Markovian equilibria. An incompetent firm's strategy, denoted by $\mu_{S}$, specifies the probability with which it chooses an $S$-name. A competent firm's strategy, 
denoted by $\left(\sigma_{S}, e_{S}, e_{N}\right)$, specifies the probability with which it chooses an $S$-name and a probability of working hard conditional on each name.

Definition 2 A steady-state equilibrium consists of strategies of firms and a price of an $S$-name, $V_{S}$ such that

1. The strategies are optimal for the firms (given the wages), and

2. Demand equals supply in the market for $S$-names at price $V_{S}$.

We do not require a market clearing condition for $N$-names which are in unlimited supply. We want to find equilibria in which the market for names solves the moral hazard problem and sorts competent and incompetent firms. So we define a sorting high effort equilibrium as follows.

Definition 3 A sorting high-effort equilibrium (SHE) is a steady-state equilibrium in which

1. There exists at least one name that is chosen by one type of firm and not by the other,

2. Each firm strictly prefers a name it chooses to one that it does not choose,

3. Competent firms strictly prefer to work hard on the equilibrium path.

This definition requires partial sorting. It turns out that the set of parameters for which SHE exist with full sorting is non-generic.

In this model, we cannot apply the standard repeated game arguments to derive the values of names that can sustain high effort. Here, the continuation payoff or the values of names cannot be chosen arbitrarily but must satisfy the market clearing conditions in the market for names.

\section{Example of SHE}

In this section, I discuss two examples of sorting high-effort equilibria. These examples demonstrate different reputational effects. In the first, incompetent firms give themselves away by being the only firms entering with cheap $N$-names. I call these SHE "Mistrust Cheap Names" or "Mistrust $N$ Names" equilibria.

Definition 4 A "Mistrust N-Names" or "Mistrust Cheap Names" equilibrium is a SHE where the incompetent type is the only one using cheap $N$-names. (S-names are used by both types)

In these equilibria, $S$-names are used by both kinds of firms. So incompetent firms are actually indifferent between $N$ and $S$-names. On the other hand, competent firms who can work hard can 
get a better continuation payoff with an $S$-name, and so strictly prefer to use $S$-names. As a result, clients treat cheap names with mistrust and pay low (zero) wages to a firm with a cheap name. I show that in a market with two names and non-random transition rules, this is the only kind of sorting that can be sustained. In the second example, I present a "Trust Expensive Names" equilibrium, where only copetent firms buy expensive names.

Definition 5 A "Trust S-Names" or "Trust Expensive Names" equilibrium is a SHE where the competent type is the only one using the valuable $S$-names. ( $N$-names are used by both types)

To demonstrate this effect, we consider a market with three kinds of firm names. (These equilibria do not exist with only two names.) There is an expensive name that only competent firms buy. The other names are used by both types of firms. In equilibrium, clients know this and when they see this expensive name, they pay the highest possible wages. Since incompetent firms are not capable of getting good outcomes, they do not find it worthwhile to pay the high price of the expensive name.

\section{1 "Mistrust Cheap Names" Equilibria: An Example}

Consider the transition rules represented by the two automata in Figure 2. We will see that with these transition rules, "Mistrust Cheap Names" equilibria can be sustained. In equilibrium, incompetent firms will reveal their type by being the only firms with cheap $N$-names.
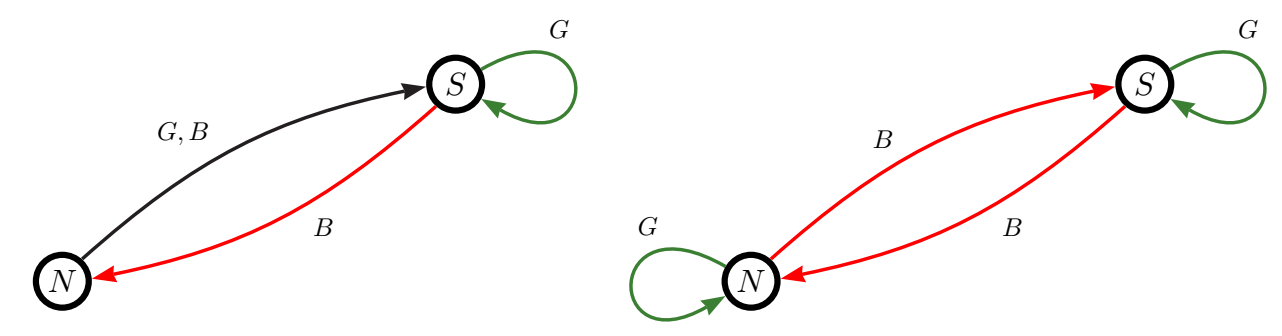

Figure 2: Transitions for "Mistrust Cheap Names" equilibria

To see why, observe that under both these rules, conditional on a bad outcome $N$-names have strictly better continuation payoffs than $S$-names. So, $I$-firms are willing to pay for $S$-names, a price $V_{S}$ which is the difference between the increase in wages from using an $S$-name and the decrease in the continuation payoff from using it. At this price, $C$-firms choose to buy $S$-names and work hard. 
Though they can be lazy, use $N$-names and still earn a higher continuation payoff, they choose not to do so, as the increase in continuation payoffs from using an $N$-name does not compensate for the decrease in wages that they suffer from using it.

So, competent firms signal their competence by buying $S$-names and then work hard to get a high continuation payoff. Incompetent firms either use a costless name and get a high continuation payoff, or they impersonate competent firms and earn high wages but lose out on continuation payoff. Proposition 1 formalizes this intuition.

Lemma 1 SHE must have C types using only S-names.

This observation enables us to prove that the above example is the only SHE sustainable with non-random transition rules and two names. To prove the lemma, I introduce some notation. Any non-random transition rule $f$ can be represented by a vector of zero's and one's $\left(f_{1}, f_{2}, f_{3}, f_{4}\right)$, where

$$
\begin{aligned}
& f(S, G)=\left\{\begin{array}{ll}
S & \text { if } f_{1}=1 \\
N & \text { otherwise }
\end{array} \quad f(S, B)= \begin{cases}S & \text { if } f_{2}=1 \\
N & \text { otherwise }\end{cases} \right. \\
& f(N, G)=\left\{\begin{array}{ll}
S & \text { if } f_{3}=1 \\
N & \text { otherwise }
\end{array} \quad f(N, B)= \begin{cases}S & \text { if } f_{4}=1 \\
N & \text { otherwise }\end{cases} \right.
\end{aligned}
$$

First consider equilibria in which $C$-firms use both $S$ and $N$-names. For $C$-firm to be indifferent between the two names, the following must be true:

$$
-V_{S}+w_{S}-c+\delta(1-\rho) f_{1} V_{S}+\delta \rho f_{2} V_{S}=w_{N}-c+\delta(1-\rho) f_{3} V_{S}+\delta \rho f_{4} V_{S}
$$

For the $C$-type to prefer working hard to being lazy on the equilibrium path, we need

$$
c<\delta(1-\rho)\left(f_{1}-f_{2}\right) V_{S} \quad \text { and } \quad c<\delta(1-\rho)\left(f_{3}-f_{4}\right) V_{S}
$$

For (2) to hold, both $S$ and $N$-names must transition to an $S$-name after a good outcome and to an $N$-name after a bad one. (i.e. $f_{1}=1, f_{2}=0, f_{3}=1$ and $f_{4}=0$ ). But by (1), this implies

$$
V_{S}=w_{S}-w_{N}
$$

A sorting equilibrium requires that $I$-firms play $S$ or $N$ but not both. So, one of the following must be true:

$$
-V_{S}+w_{S}+\delta f_{2} V_{S}<(>) w_{N}+\delta f_{4} V_{S}
$$


Since $f_{2}=f_{4}=0$, this implies that $V_{S}>(<) w_{S}-w_{N}$, contradicting (3). Next, consider sorting equilibria in which the $C$-type uses only $N$-names. Then, the $I$-type must use $S$-names. So the following must be true:

$$
V_{S} \leq w_{S}-w_{N}+\delta V_{S}\left(f_{2}-f_{4}\right)
$$

But, in this equilibrium, $w_{S}=0 \leq w_{N}$. This implies that $V_{S} \leq 0$, which is not possible. If $V_{S} \leq 0$, this would destroy incentives for $C$-firms to work hard in any state. This concludes the proof.

The intuition for the second part is that since only $I$-types buy $S$-names, there is no benefit in wages from an $S$-name. $I$-types buy $S$-names only because an $S$-name gives a better (weakly) continuation payoff than an $N$-name in case of a bad outcome. Therefore, at best an $I$-firm gets a continuation payoff of $\delta V_{S}$, but must pay $V_{S}$ for it. This will leave the $I$-firm with a non-positive net payoff. So it cannot be that incompetent firms buy $S$-names. This contradicts the hypothesis. So, in equilibrium $C$-types can play only $S$-names.

Proposition 1 Sorting high-effort equilibria exist in the market with non-random transitions if and only if

$$
\phi \leq \frac{1}{1+\rho} \text { and } c<\frac{2 \delta \phi(1-\rho)^{2}}{(1+\delta)(1+\phi-\phi \rho)} .
$$

The equilibria can be characterized as follows:

1. Competent firms buy only $S$-names.

2. Incompetent firms buy $S$-names with probability $\mu_{S}=\frac{1}{2}-\frac{\rho \phi}{2(1-\phi)}$.

3. Firms earn wages that equal the expected utility to the consumer conditional on the firm's name, $w_{S}=\frac{\phi(1-\rho)}{\phi+(1-\phi) \mu_{S}}$ and $w_{N}=0$.

4. $S$-names trade at price $V_{S}=\frac{w_{S}}{1+\delta}$.

The interested reader may refer to the appendix for the proof of Proposition 1. Notice that if the proportion of competent types is very high (i.e. for $\phi>\frac{1}{1+\rho}$ ), there will be a shortage of $S$-names in the market. There will be a high demand for $S$-names but there will be insufficient incompetent firms creating $S$-names. So the market for $S$-names cannot clear.

When $\phi<\frac{1}{1+\rho}$, the equilibria characterized above are partially sorting equilibria in that $S$-names are bought by both types of firms, but only incompetent firms use $N$-names. At the knife-edge case $\phi=\frac{1}{1+\rho}$, full separation can be sustained, where $C$-firms use $S$-names and $I$-firms use $N$-names.

An important feature of this equilibrium is that it remains an equilibrium even if consumers could observe not only the name of the firm but also the complete history of outcomes of the name. This is an appealing property because it implies that the existence of the SHE above is not 
dependent on the implementation of any specific transition rule. (Refer to Section 4.4.1 for further discussion of this property.)

\section{2 "Trust Expensive Names" Equilibria: An Example}

Proposition 1 establishes that the only SHE that exist with two names and non-random transition rules are of the "Mistrust Cheap Names" type. The next example therefore uses a richer market with three possible firm names to demonstrate "Trust Expensive Names" equilibria under nonrandom transition rules. There is a valuable firm name that is bought only by competent firms. The other names are bought by both types of firms. Competent firms work hard in equilibrium.

\subsubsection{A Richer Market for Names}

Consider a richer market for names with three names: $S_{1}, S_{2}$ and $S_{3}$. Without loss of generality, let $S_{3}$ be the cheapest name with its price normalized to 0 . Denote the wages conditional on the name by $w_{1}, w_{2}$ and $w_{3}$. I restrict attention again to non-random transition rules which are functions $f:\left\{S_{1}, S_{2}, S_{3}\right\} \times\{G, B\} \rightarrow\left\{S_{1}, S_{2}, S_{3}\right\}$. An incompetent firm's strategy, denoted by $\left(\mu_{1}, \mu_{2}, \mu_{3}\right)$, specifies the probability with which it chooses $S_{1}, S_{2}$ and $S_{3}$-names respectively. A competent firm's strategy, denoted by $\left(\sigma_{1}, \sigma_{2}, \sigma_{3}, e_{1}, e_{2}, e_{3}\right)$, specifies the probabilities with which it chooses

$S_{1}, S_{2}$ and $S_{3}$-names respectively, and the probability of working hard conditional on each name. The definitions of equilibrium and sorting high-effort equilibrium can be extended to this richer environment in a natural way.

Definition 6 A steady state equilibrium for a given transition rule consists of strategies of firms and prices of names $V_{1}$ and $V_{2}$ such that

1. The strategies are optimal for the firm (given the transition rule and the wages), and

2. Demand equals supply in the markets for $S_{1}$ and $S_{2}$-names at prices $V_{1}$ and $V_{2}$ respectively.

Definition 7 A sorting high-effort equilibrium (SHE) is a steady-state equilibrium in which

1. There exists at least one name that is chosen by one type of firm and not by the other,

2. Each firm strictly prefers the names it chooses to those it does not choose, and

3. Competent firms choose to work hard on the equilibrium path.

Note that I assume that firms work hard on and off the equilibrium path. This is just a convenient assumption. If this restriction were dropped, SHE would exist for a larger set of parameters. 
We can extend the definition of "Trust Expensive Names" equilibria in a similar way.

Definition 8 A "Trust Expensive Names" equilibrium is a SHE in which there is some valuable name that is bought only by competent firms. (The other names may be bought by both types.)

\subsubsection{Example}

Consider transition rules given by the automaton in Figure 3 below.

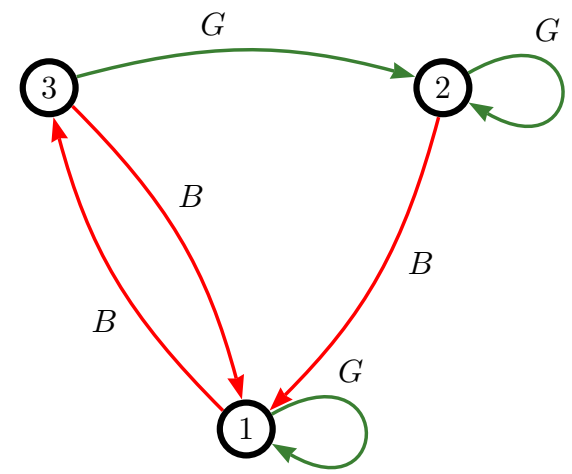

Figure 3: Transition for "Trust Expensive Names" Equilibria

We show that with these transition rules, "Trust Expensive Names" equilibria exist. In these equilibria, competent firms are the only ones buying $S_{1}$-names. $S_{2}$ and $S_{3}$-names are bought by both types. Competent firms work hard irrespective of the name they enter with. There are other transition rules which also give rise to SHE. Refer to the appendix for a description of all SHE sustainable under non-random transition rules in this richer market with three names. The necessary and sufficient conditions for such an equilibrium are as follows:

\section{Incentive Compatibility for Name Choice}

Competent firms are indifferent between $S_{1}$ and $S_{3}$-names.

$$
-V_{1}+w_{1}-c+\delta(1-\rho) V_{1}=w_{3}-c+\delta(1-\rho) V_{2}+\delta \rho V_{1} \Longrightarrow V_{1}=\frac{w_{1}-w_{3}-\delta(1-\rho) V_{2}}{1+\delta \rho-\delta(1-\rho)}
$$

Competent firms are indifferent between $S_{2}$ and $S_{3}$-names.

$$
-V_{2}+w_{2}-c+\delta(1-\rho) V_{2}+\delta \rho V_{1}=w_{3}-c+\delta(1-\rho) V_{2}+\delta \rho V_{1} \Longrightarrow V_{2}=w_{2}-w_{3}
$$

Incompetent firms must strictly prefer an $S_{3}$-name to an $S_{1}$-name.

$$
w_{3}+\delta V_{1}>-V_{1}+w_{1} \Longrightarrow V_{1}>\frac{w_{1}-w_{3}}{1+\delta}
$$


Incompetent firms must be indifferent between $S_{3}$ and $S_{2}$-names.

$$
w_{3}+\delta V_{1}=-V_{2}+w_{2}+\delta V_{1} \Longrightarrow V_{2}=w_{2}-w_{3}
$$

Incentive for Competent Firms to Work Hard

Competent firms prefer working hard to being lazy irrespective of the name they enter with.

$$
c<\delta(1-\rho) V_{1} \quad \text { and } \quad c<\delta(1-\rho)\left(V_{2}-V_{1}\right)
$$

\section{Market Clearing Conditions}

$$
\begin{gathered}
S_{1} \text { names: } \quad \phi \sigma_{1}=\phi \sigma_{1}(1-\rho)+\phi \sigma_{2} \rho+\phi\left(1-\sigma_{1}-\sigma_{2}\right) \rho+(1-\phi) \mu_{2}+(1-\phi)\left(1-\mu_{2}\right) \\
\Longrightarrow \quad \sigma_{1}=\frac{1-\phi+\phi \rho}{2 \phi \rho} \\
S_{2} \text { names: } \quad \phi \sigma_{2}+(1-\phi) \mu_{2}=\phi \sigma_{2}(1-\rho)+\phi\left(1-\sigma_{1}-\sigma_{2}\right)(1-\rho) \\
\Longrightarrow \quad \sigma_{2}=\frac{1-\rho}{2}-\frac{(1-\rho)(1-\phi)}{2 \phi \rho}-\frac{1-\phi}{\phi} \mu_{2}
\end{gathered}
$$

Wages $w_{1}, w_{2}, w_{3}$ just equal the expected utility to the consumer. It can be easily verified that the above equations and inequalities admit a non-empty solution set.

There are two interesting features of this example. First notice that when a consumer sees an $S_{1}$-name, she knows with certainty that the firm is a competent one. There is no uncertainty about the type, and yet competent firms still choose to work hard. This is contrary to standard reputation models in which it is the uncertainty about a player's type that forces effort exertion.

Second, notice that a richer market for names can extend the range of equilibria. From (9), we see that for $\sigma_{1}$ to lie in the interval $(0,1)$, we need $1-\phi+\phi \rho<2 \phi \rho$. In other words, the equilibrium conditions in this example imply that $\phi>\frac{1}{1+\rho}$. But these are precisely the conditions for which equilibria do not exist in the first example in a market with two names. So there exist SHE in the richer market with non-random transition rules which are not possible in the two-state market.

\section{Markets with General Transition Rules}

With two states and non-random transition rules our ability to sustain SHE seems limited. It is not possible to sustain "Trust $S$-Names" equilibria. Further, even if the cost of working hard is very small, it is not possible to sustain SHE if there are too many competent firms (high $\phi$ ) or if the chance of failing $(\rho)$ is high. Section 3.2 suggests one way of sustaining more SHE: by enriching the market with more states. 
An alternate approach could be to consider more general transition rules. Why might this approach work? The following example illustrates why. With a non-random transition rule, the original name and outcome together determine with certainty the future name of the firm. Suppose now that $N$-names were 'disadvantaged' in the sense that even after a good outcome $N$-names found it harder to become $S$-names. (Formally, conditional on a good outcome the future of a firm with an $\mathrm{N}$-name is determined by the realization on an independent idiosyncratic randomization device. With a strictly positive probability, $N$-names remain worthless even after a good outcome.) $S$-names do not suffer this disadvantage, i.e. conditional on a good outcome, an $S$-name remains an $S$-name with certainty. Conditional on a bad outcome, any name becomes worthless. If such a transition rule were prevalent, a competent firm would be willing to pay a strictly higher premium for $S$-names compared to an incompetent firm. An incompetent firm is willing to pay a price up to the increase in wages it gets from an $S$-name. A competent firm is willing to pay this and more. A $C$-firm is also willing to pay for the increase in expected continuation payoffs from an $S$-name (conditional on working hard). This would be enough to yield "Trust $S$-Names" equilibria, as sorting only requires that one type be willing to pay a strictly higher premium for an $S$-name than the other type.

This idea leads us to ask: If we use more general transition rules, what are the conditions under which SHE can be sustained without further enriching the market for names? This section addresses this question. I conjecture that a two-state market with random transitions is only an efficient way of representing a richer market with deterministic transitions. In other words, for any SHE with random transitions in the two-state market, it is possible to find a deterministic transition rule that can sustain an equivalent SHE in a market endowed with more names.

Definition 9 Define a general transition rule to be a function $f:\{S, N\} \times\{G, B\} \rightarrow \Delta(\{S, N\})$, where $\Delta(\{S, N\})$ represents the probability distributions over the states $\{S, N\}$. So, a general transition rule $f$ can be described completely by a vector $\left(\gamma_{1}, \gamma_{2}, \gamma_{3}, \gamma_{4}\right)$, where

$f(S, G)=\left(\gamma_{1}, 1-\gamma_{1}\right) \quad f(S, B)=\left(\gamma_{2}, 1-\gamma_{2}\right) \quad f(N, G)=\left(\gamma_{3}, 1-\gamma_{3}\right) \quad f(N, B)=\left(\gamma_{4}, 1-\gamma_{4}\right)$

Here, $f(S, G)=(\gamma, 1-\gamma)$ denotes that conditional on outcome $G$, an $S$-name will transition to $S$ with probability $\gamma$ and to $N$ with probability $1-\gamma$.

Notions of strategies and equilibrium are unaltered. We start with the following observation.

Lemma 2 In any SHE, some competent firms must buy S-names. 
Proof: Suppose there exists an equilibrium in which competent firms buy only $N$-names (the cheap name). Sorting implies that incompetent firms must use the valuable $S$-names. In other words, an $I$-type prefers (at least weakly) an $S$-name to an $N$-name.

$$
-V_{S}+w_{S}+\delta \gamma_{2} V_{S} \geq w_{N}+\delta \gamma_{4} V_{S}
$$

Since in such an equilibrium, $w_{S}<w_{N}$, the above expression would imply that $V_{S}$ is negative irrespective of the values of $\gamma_{2}$ and $\gamma_{4}$. This is a contradiction as $V_{S}$ is the valuable name.

To see the intuition, consider the incentives for incompetent firms. A name affects incentives via wages or via continuation payoffs. In an equilibrium in which $C$-firms buy only $N$-names, an $S$-name would always give lower wages than an $N$-name. So the only reason for an incompetent type to buy an $S$-name is that it gives higher continuation payoffs than an $N$-name, after accounting for the price paid for the $S$-name. At best, an $S$-name will give a discounted continuation payoff of $\delta V_{S}$, which means that net payoff from an $S$-name is really negative. At worst, an $N$-name will give a net payoff of 0 . So, it cannot be that incompetent firms prefer buying $S$-names to $N$-names.

\subsection{Characterizing the Region where SHE Exist}

By the lemma above, $C$-firms must buy $S$-names and $I$-firms must buy $N$-names in SHE. This leaves us with only two possible kinds of sorting. These are in fact the types of sorting we observed in the examples in Section 3.

The first is "Trust $S$-names" sorting. Here, only competent firms buy successful names. $C$-firms use both $N$ and $S$-names. $I$-firms use only $N$-names. So, competent firms signal their competence by buying $S$-names, and incompetent cannot impersonate competent firms by buying $S$-names because the price is too high to make it worthwhile. Consumers trust an $S$-name when they see it, because they are certain that it is owned by a competent firm.

The second type of sorting is "Mistrust $N$-names". Here, only incompetent firms enter with new names. $S$-names are used by both $C$ and $I$-firms. Competent firms do not use $N$-names because if they work hard, the costly $S$-names still give them a higher expected payoff than $N$-names. Consumers mistrust any $N$-name, because they are certain that it is owned by an incompetent firm.

Recall that our objective is to characterize the conditions under which it is possible to find transition rules which result in sorting high-effort equilibria. It turns out that there is a simple characterization of the conditions for existence. SHE exist if and only if the cost of effort is low 
enough.

Proposition 2 Given $\phi, \rho, \delta, c$, a sorting high-effort equilibrium exists if and only if

$$
c<\bar{c}=\min \left\{\frac{\delta(1-\phi)(1-\rho)^{2}}{1-\phi+\delta \phi \rho}, \frac{\delta(1-\phi)(1-\rho)^{2}}{\delta(1-\phi)+\phi \rho}\right\}
$$

The interested reader may refer to the appendix for the proof. Note that the upper bound $\bar{c}$ is decreasing in $\phi$. In other words, as the proportion of competent firms increases, it becomes harder to maintain a high-effort sorting equilibrium. To see why, notice first that if almost all firms are competent, (as $\phi \rightarrow 1$ ) the consumer will pay very similar wages to firms with $S$ and $N$-names (i.e. $\left.\left(w_{S}-w_{N}\right) \rightarrow 0\right)$. In all sorting equilibria, we have seen that the price of an $S$-name is always less than or equal to the difference in wages. As a result, the price of an $S$-name will approach zero as well. If there is no benefit from ending up with an $S$-name, the incentives for working hard will be lost.

The upper bound $\bar{c}$ is also decreasing in $\rho$. The intuition is straightforward. If the probability of a bad outcome conditional on working hard is reduced, competent firms have a better incentive to work hard. At the other extreme, if hard work resulted in a bad outcome for sure $(\rho=1)$, there would be no incentive to work hard, and a high-effort equilibrium would be impossible. Indeed, at $\rho=1, c$ needs to be negative.

Given any cost of effort $c<\bar{c}$, one may ask whether both types of SHE exist for this cost. It turns out that the conditions for existence of "Trust $S$-Names" equilibria alone are more restrictive. "Trust $S$-Names" equilibria exist if and only if the cost of effort is lower than a threshold $\frac{\delta(1-\phi)(1-\rho)^{2}}{1-\phi+\phi \rho}$. Notice that for impatient firms, this threshold is strictly smaller than $\bar{c}$. Hence, above this threshold cost, the only SHE that exist are of the "Mistrust $N$-Names" type. For perfectly patient firms, the thresholds are the same, and hence both types of SHE exist for any cost $c<\bar{c}$.

\subsubsection{HE and SHE}

As an aside, let us examine the relationship between observability and sorting. The sorting feature of equilibrium arises naturally in a model with observability of name trades. The rough intuition is as follows: For names to be valuable, consumers must be able to trust a good name even when they know that it has just been sold to a new owner. This is possible if one of two situations arise: Consumers may be sure that only competent firms can buy good names. Alternatively, consumers must believe that new names cannot be trusted, as only incompetent firms choose to enter with new names. Successful names are valuable (tradeable) if some form of sorting arises in equilibrium. 
It turns out that under observability, sorting does not restrict the range of parameters where high-effort equilibria exist. Define high-effort equilibrium with no sorting as follows:

Definition 10 (High-effort Equilibrium) A high-effort equilibrium without sorting (HE) is a steady-state equilibrium in which

1. There is no name that is chosen by one type of firm and not by the other, and

2. Competent firms strictly prefer to work hard on the equilibrium path.

Proposition 3 Given $\phi, \rho, \delta, c$, a high-effort equilibrium (HE) exists if and only if

$$
c<\frac{\delta(1-\phi)(1-\rho)^{2}}{1-\phi+\phi \rho}
$$

This proposition is proved using identical methods as Proposition 2, and so the proof is omitted. Notice that the upper bound for costs is lower in the case of HE. This implies that the requirement for separation in equilibrium is not a restrictive one. By relaxing the requirement of sorting, we cannot expand the range of parameter values where high-effort equilibria exist. In a sense, in high-effort equilibria under observability, we get the sorting feature for free.

Below we return to analyzing the SHE. The next two propositions characterize each type of sorting that arises in terms of the transition rule, costs and primitives of the environment.

\subsection{Trust $S$-Names Equilibria}

What kind of transition rules can create "Trust $S$-names" equilibria? Intuitively, transition rules must display three properties:

1. For $C$-firms to be indifferent between $S$ and $N$-names, the price of an $S$-name must be exactly equal to the sum of increase in wages and increase in expected continuation payoffs conditional on working hard. For $I$-firms to avoid $S$-names, the price must be higher than the increase in wages and the increase in continuation payoffs conditional on a bad outcome.

2. Transition rules must be such that the demand for $S$-names equal the supply.

3. For $C$-firms to have a strict incentive to work hard in every state, transitions must ensure that the expected payoff from working hard is strictly higher than that from being lazy.

The following proposition describes these properties formally. 
Proposition 4 (Trust S-Names Equilibria) High-effort "Trust S-names" equilibria exist if and only if

1. $\gamma_{3}-\gamma_{4}<\gamma_{1}-\gamma_{2}$

2. $\gamma_{4}<\frac{\phi}{1-\phi}\left(1-(1-\rho) \gamma_{1}-\rho \gamma_{2}\right)$

3. $c<\delta(1-\rho)\left(\gamma_{3}-\gamma_{4}\right) \frac{(1-\phi)(1-\rho)}{\left[\phi\left(1-\sigma_{S}\right)+1-\phi\right]\left[1+\delta(1-\rho)\left(\gamma_{3}-\gamma_{1}\right)+\delta \rho\left(\gamma_{4}-\gamma_{2}\right)\right]}$

where $\sigma_{S}=\frac{\phi(1-\rho)\left(\gamma_{3}-\gamma_{4}\right)+\gamma_{4}}{\phi(1-\rho)\left(\gamma_{3}-\gamma_{1}\right)+\phi \rho\left(\gamma_{4}-\gamma_{2}\right)+\phi}$.

So, for a given distribution of firms $\phi$, success rate $(1-\rho)$ and discount factor $\delta$, transition rules which satisfy conditions (1) and (2) can sustain high-effort "Trust $S$-names" equilibria, provided the cost of working hard is sufficiently low (i.e. (3) holds). For the proof, the reader may refer to the appendix. We get an analogous result for "Mistrust $N$-names" equilibria.

\subsection{Mistrust $N$-Names Equilibria}

In "Mistrust $N$-Names" equilibria, what must transition rules look like?

1. For incompetent firms to use $S$ and $N$-names, the price of an $S$-name must be exactly equal to the increase in wages and increase in the continuation payoffs conditional on a bad outcome. For $C$-firms to not use $N$-names, the price of an $S$-name must be less than the total increase in wages and continuation payoff conditional on hard work.

2. The market for $S$-names must clear.

3. $C$-firms must work hard on the equilibrium path i.e. when they buy $S$-names.

Proposition 5 ("Mistrust N-Names" Equilibria) High-effort "Mistrust N-names" equilibria exist if and only if

1. $\gamma_{3}-\gamma_{4}<\gamma_{1}-\gamma_{2}<\frac{1-\gamma_{2}}{\phi(1-\rho)}$

2. $\gamma_{4}>\frac{\phi}{1-\phi}\left(1-(1-\rho) \gamma_{1}-\rho \gamma_{2}\right)$

3. $c<\delta(1-\rho)\left(\gamma_{1}-\gamma_{2}\right) \frac{\phi(1-\rho)}{\left[\phi+(1-\phi) \mu_{S}\right]\left[1+\delta\left(\gamma_{4}-\gamma_{2}\right)\right]}$

where $\mu_{S}=\frac{\phi(1-\rho) \gamma_{1}+\phi \rho \gamma_{2}+(1-\phi) \gamma_{4}-\phi}{(1-\phi)\left(1+\gamma_{4}-\gamma_{2}\right)}$.

For a proof of the Proposition 5, the reader may refer to the appendix. The conditions for the existence of "Mistrust $N$-Names" equilibria turn out to be more permissive than those for "Trust $S$ Names". In "Mistrust $N$-Names" equilibria competent firms use only $S$-names. Since $N$-names are off the equilibrium path for $C$-firms, and it is no longer necessary to sustain high-effort conditional 
on an $N$-name. This makes it possible to sustain high-effort and sorting for some parameter ranges where "Trust $S$-Names" are unsustainable.

\subsection{Non-Random Transitions as a Special Case}

It can be easily verified that the example of SHE with non-random transition rules described in Section 3.1 satisfies the conditions in Proposition 5. From Propositions 4 \& 5, it can be seen why these are the only non-random rules that work. Consider all possible non-random transition rules in the two-state market. To maintain incentives for competent firms to work hard, all rules which do not reward an $S$ name for a good outcome are eliminated. (i.e. rules with $\gamma_{1} \leq \gamma_{2}$ ). This leaves possible only four transition rules.

$$
\begin{array}{rrrr}
(1,0,1,0) & (1,0,0,0) & (1,0,1,1) & (1,0,0,1) \\
(a) & (b) & (c) & (d)
\end{array}
$$

Rule (a) violates Condition 1 for both types of equilibria and cannot ensure sorting. Rule (b) destroys incentives for hard work in both types of equilibria. Rules (c) and (d) destroy effort incentives in the "Trust $S$-names" case. This leaves only rules (c) and (d) as options to sustain "Mistrust $N$-names" equilibria, which are precisely the ones described in Section 3.1.

\subsubsection{Equilibrium when Clients Observe Full History of Outcomes}

The SHE with non-random transitions satisfy another interesting property. These equilibria survive in the more standard infinitely repeated game setting where consumers can see not just the name but the full history of outcomes for any firm name that they encounter.

To elaborate, let us consider a slightly different environment, where a name is a complete history of outcomes $(G$ or $B)$ of the firms that owned it. So, when consumers see a name what they observe is the complete history of outcomes. Note that since play has occurred for ever into the past, consumers observe an infinite history of outcomes. The timing of the game is unaltered. As before, firms must choose a name before they enter. Retiring firms sell their name if possible. A new firm can choose to enter costlessly with a new name (with no history) $N$ or with a name bought from a retiring firm. In this setting, we want to look for sorting high-effort equilibria. In other words, can we find equilibria where competent firms always exert high effort, and there is at least one kind of name which perfectly signals the type of the firm that uses it? 
In this setting, since names are now just histories, firms can choose between potentially infinitely many different names. On the face of it, this would complicate the problem significantly. We can simplify the problem by considering certain equivalence classes of outcome histories. Denote the entire set of possible outcome histories by $\mathscr{H}$ and any arbitrary history by $h$. Consider two equivalence classes of $\mathscr{H}$, denoted by $\mathscr{N}$ and $\mathscr{S}$, defined as follows:

Let $N \in \mathscr{N}$

$h \in \mathscr{S} \Longrightarrow h B \in \mathscr{N}, h G \in \mathscr{S}$

$h \in \mathscr{N} \Longrightarrow h B, h G \in \mathscr{S}$

To illustrate, the history $N G B$ belongs to $\mathscr{N}$ while $N G B B$ belongs to $\mathscr{S}$.

Clients will treat any two histories in the same equivalence class in the same way. In effect, clients behave as if firms appear under two names $\mathscr{N}$ and $\mathscr{S}$. It can be easily verified that the following constitutes a steady-state equilibrium in this game.

- $\mathscr{N}$-names are worthless. $\mathscr{S}$-names sell at a price $V_{S}$ as in Proposition 1.

- $C$-firms always enter with $\mathscr{S}$-names.

- $I$-firms use $\mathscr{S}$-names with probability $\mu_{S}$ as in Proposition 1 and $\mathscr{N}$-names with $1-\mu_{S}$.

When a consumer sees a name from $\mathscr{N}$, she believes that the firm must be an incompetent one and so pays a wage of $w_{N}=0$. When she sees a name from $\mathscr{S}$, she knows the firm could be a $C$ or an $I$-firm, and pays her expected utility $w_{S}$ as given in Proposition 1.

So, we have found an exact analog of the "Mistrust $N$-names" equilibrium derived in the economy with two kinds of names and non-random transition rules. Why is this a desirable property? In our model, a transition rule is a mechanism (conceivably managed by a mediator) that determines the future of a firm based on its original name, realized outcome and an independent idiosyncratic randomization. SHE that arise seem to depend critically on implementation of the transition rule. However, we see here that the SHE that are sustainable with non-random transitions are not really dependent on the existence of any mediator or transition mechanism. They can arise naturally in equilibrium in a standard repeated game environment where all players can observe the history of realized outcomes. This property does not hold for SHE under random transitions. However, I conjecture that for any SHE in the two-state market with random transitions, an equivalent one can be derived using non-random rules in a market with a richer set of names. In that case, we would be able to use a richer set of equivalence classes of histories and remove the dependence of SHE on specific transition rules. 


\section{Relaxing Observability}

So far, we have considered an environment where name trades are fully observable, and derived sorting high-effort equilibria. An interesting extension would be a comparison of this environment with one with non-observability of name ownership changes, in terms of existence of SHE and welfare implications. A detailed examination of these issues is not included in the scope of this paper. In this section, I present some examples to illustrate how the welfare comparisons can go in either direction, based on the specific transitions rules being implemented and the primitives of the environment. In the model described so far, observability is automatic. In order to make a meaningful comparison between regimes with and without observability, we need to alter the environment.

\subsection{Overlapping Generations Model}

Consider an economy with overlapping generations of firms. As before there are two types of firms, competent and incompetent. A proportion $\phi$ is competent. Competent firms can choose to work hard and incompetent firms are incapable of working hard. There are two outcomes - good $(\mathrm{G})$ and bad(B). Conditional on hard work, the probability of a good outcome is $(1-\rho)$, and conditional on laziness, a good outcome never occurs.

Each firm lives two periods. Firms can enter with $N$ or $S$-names. Firms meet consumers once in each period. Retiring firms sell their name before retiring. Consider the general random transition rules described in Section 4. Conditional on a good outcome, an $S$-name remains an $S$-name with probability $\gamma_{1}$ and $N$-names become $S$ with probability $\gamma_{2}$. Conditional on a bad outcome, $S$-names remain $S$-names with probability $\gamma_{3}$ and $N$-names become $S$-names with probability $\gamma_{4}$. The timing of the game is depicted in Figure 4.

In any period there are three generations of firms - nascent firms who are just entering the market, old firms who have already lived for one period and retiring ones. Only retiring firms can sell names to nascent firms. Old firms cannot buy or sell names. (This is just a convenient assumption. The qualitative results are unaltered if old firms also bought names.)

At the time of entry, a firm decides what name to enter with. It can enter costlessly with a neutral $(N)$ name, or can buy a costly name from a retiring firm. On entering, firms meet a consumer who pays the firm an upfront wage. Then the firm takes an action (work hard or be lazy), and conditional on the action choice and outcome, the firm's name changes. The firm meets 


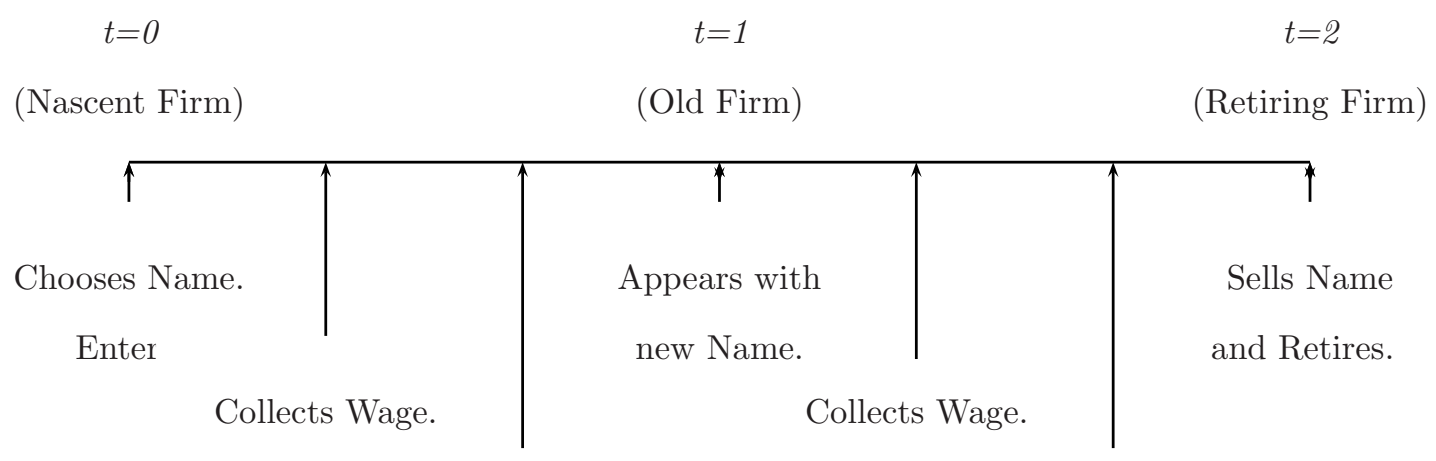

Takes Action.

Takes Action.

Name Changes.

Name Changes.

Figure 4: Timing of Game for Overlapping Generations of Firms

a consumer again in the second period now with his altered name. Again, he collects his wage, takes an action, and his name changes. Before retiring the firm sells its name (if possible) to a nascent firm. For simplicity, we ignore discounting.

Consumers live only one period. They pay firms upfront, and so pay the expected utility based on what they observe. In this model, we can study the two regimes with and without observability of name ownership. In a regime of non-observability, consumers see only the name of the firm. Under observability, they see not just the name but also the age of the firm. The age of a nascent firm is 0 and the age of an old firm is 1 . This is equivalent to full observability of name: for instance, a nascent $S$-name must be a firm which just bought the name. Denote the wages by $w_{N, 0}, w_{N, 1}, w_{S, 0}, w_{S, 1}$, where $w_{a, i}$ denotes the wage paid to a firm with name $a$ and age $i$. Notions of strategies and equilibrium are extended in the natural way.

\subsection{Observability and Welfare: Examples}

When we compare regimes of observability and non-observability, it is clear that since we consider only high-effort equilibria the total surplus of consumers and firms is constant. The more interesting question is to ask separately whether the consumers are better off under any particular regime. Alternatively, which firms fare better under which regimes?

While a general analysis is postponed to later work, the examples presented here illustrate the 
different effects that may arise. To compare meaningfully, I choose examples where equilibria exist both under observability and non-observability. In the first example, observability is irrelevant. The wages paid are independent of the age of the firm. In later examples I show that it is possible for all firms to get better off under one regime or the other. I also present examples where the preferences of the two types of firms are opposed.

\subsubsection{Observability makes no difference}

Consider a market with the following transition rule. Conditional on a bad outcome, all names become $N$-names. Conditional on a good outcome, $S$-names remain $S$-names and $N$-names become $S$ with probability $(1-\lambda) \in(0,1)$. Consider a "Trust $S$-Names" equilibrium. When consumers see an $S$-name, they know that it is a good firm, and will pay $w_{S, 0}=w_{S, 1}=1-\rho$. A nascent firm with an $N$-name can be competent or incompetent. Hence, the consumer pays her expected utility

$$
w_{N, 0}=\frac{\phi\left(1-\sigma_{S}\right)(1-\rho)}{\phi\left(1-\sigma_{S}\right)+1-\phi}
$$

For old firm with an $N$-name there are three possibilities. The firm may be an incompetent one, or a competent firm who had an $N$-name and remained $N$, or a competent firm who had an $S$-name but ended up with an $N$-name. Again, the consumer pays her expected utility

$$
w_{N, 1}=\frac{\phi\left(1-\sigma_{S}\right)(\rho+\lambda(1-\rho))+\phi \sigma_{S} \rho}{1-\phi+\phi\left(1-\sigma_{S}\right)(\rho+\lambda(1-\rho))+\phi \sigma_{S} \rho}(1-\rho)
$$

We can solve for the high-effort sorting equilibrium. It turns out that $C$-firms buy $S$-names with probability $\sigma_{S}=\frac{(1-\rho)(1-\lambda)}{1-\lambda+\lambda \rho}$. I-firms use only $N$-names. The equilibrium price $V_{S}$ is

$$
V_{S}=\frac{w_{S, 0}-w_{N, 0}+\lambda(1-\rho)\left(w_{S, 1}-w_{N, 1}\right)}{1-\lambda^{2}(1-\rho)^{2}} .
$$

What happens if we impose the condition that ownership changes cannot be observed? It turns out that this makes no difference to the equilibrium in this market. To see why, recall that any firm with an $S$-name must be competent, and so earns a wage $w_{S, 0}=w_{S, 1}=1-\rho$. The wages earned by firms with $N$-names turns out to be

$$
w_{N, 0}=w_{N, 1}=\frac{\phi \rho}{\phi \rho+(1-\phi)(1-\lambda+\lambda \rho)}
$$

Since the wages paid are always independent of the age of the firm, making ownership changes unobservable does not make any difference to firms or consumers. 


\subsubsection{All firms prefer one regime}

Consider a market where the proportion of $C$-firms $\phi=0.9$ and the cost of effort $c=0.1$. The market has the following transition rule: Conditional on a good outcome, both $S$ and $N$-names become $S$-names. Conditional on a bad outcome, $S$-names remain $S$ with probability 0.1 and $N$-names become $S$ with probability 0.2 . (i.e. $\gamma_{1}=\gamma_{3}=1, \gamma_{2}=0.1, \gamma_{4}=0.2$ ).

Example 1 (All firms prefer non-observability) Let $\rho=0.1$. Under these conditions, under observability, there exists a "Trust $S$-names" equilibrium. If name changes were not observable, the same equilibrium survives, and it can be verified that all firms get better off.

Example 2 (All firms prefer observability) Let $\rho=0.01$. Under these conditions, under observability, there exists a "Mistrust $N$-names" equilibrium. If name changes were not observable, the same equilibrium survives, but now all firms can be shown to get worse off.

The net payoff from buying or selling a name is weakly negative. The price of an $S$-name is higher in a regime with observability. This implies that under observability, name trading is more costly for any firm. A firm will prefer observability only if the sum of the wages it receives is high enough to cover the increased cost of name trade.

\subsubsection{Different firms prefer different regimes}

Now suppose the proportion the cost of working hard $c=0.1$ and the probability of a bad outcome conditional on working hard is $\rho=0.01$.

Example 3 ( $C$-firms prefer non-observability, I-firms prefer observability) Suppose $\phi=$

0.95. Consider the following transition rule. Conditional on a good outcome, an $S$-name remains an $S$-name with probability 1. Conditional on a bad outcome, an $S$-name remains $S$ with probability 0.2. The corresponding transition probabilities for an $N$-name are 0.8 and 0.1 . Under observability there exists a "Trust S-names" equilibrium. If ownership changes were not observable, the same equilibrium survives. C-firms get better off while I-firms lose out. However, together the firms get better off and consequently, consumers get worse off.

Example 4 ( $C$-firms prefer observability, $I$-firms prefer non-observability) Let $\phi=0.5$. Consider the transition rule as above with one difference. Now conditional on a good outcome, an $S$-name remains $S$ with probability 0.95 . Under observability there exists a "Mistrust $N$-names" 
equilibrium. If ownership changes were not observable, the same equilibrium survives. Now, $C$ firms get worse off while I-firms get better off. Together, the firms get worse off and so consumers get better off.

Observe that, in "Trust $S$-names equilibria", observability makes consumers weakly better off, while in "Mistrust $N$-names" equilibria with consumers get worse off under observability.

\section{Related Literature}

This paper contributes to the growing literature on firm reputations and the market for firm reputations. Earlier work closest in spirit to this paper would include Kreps (1990) and Tadelis (1999, 2002, 2003). In this and related work, the existence of a market for firm names plays two roles. A tradeable name provides incentives for short-lived agents to work hard. Also, a firm name acts as an assessment of firm's ability, and tradeable names allow firms to buy credibility with consumers.

Tadelis $(1999,2002,2003)$ considers a general equilibrium framework where he establishes a link between the value of the name and price of the firm's services. Unlike this work, Tadelis (1999, 2003) considers a model of pure adverse selection. Tadelis (2002) includes moral hazard. One of the key insights from Tadelis's work is that non-observability of ownership changes is key to active name trading in all equilibria.

In the current paper, I depart from the literature by examining whether active trading of firm names can exist with observability of ownership changes. I present a model with both adverse selection and moral hazard and with full observability of name trading. I show that in this environment, all high-effort equilibria involve active trading of names. However, we cannot eliminate the 'bad' equilibrium in which all firms are lazy, consumers mistrust all firms, firms earn nothing and names are not traded. Since the 'commitment' type in my model is an incompetent lazy type, this equilibrium cannot be eliminated.

In a recent paper, Hakenes and Peitz (2007) also ask the question whether firm names can be traded when ownership changes are observable. They derive sorting equilibria with observability, but in a model of pure adverse selection. Further, they do not allow full observability and are able to obtain active trading only with partial observability. In their set-up, all consumers cannot observe names of firms. Firm reputations are observable locally to a subset of consumers.

The other feature that sets this paper apart is the sorting nature of equilibrium. Sorting of types does not arise in equilibrium in the Tadelis environment. This is a result of two opposing 
effects. On one hand, good firms value good names because they can work hard and maintain them. On the other hand, bad firms value existing good names because they cannot build a reputation for themselves. When good firms try to separate themselves by buying good names, the second effect overwhelms the first and bad firms value good names more than good firms.

Mailath and Samuelson (2001) also consider a market for firm reputations in which types cannot get sorted. They show that names of intermediate value are more likely to be bought by good firms and names with extreme reputations are more likely to be bought by bad firms. Very good names are more attractive to bad firms who will gain by depleting the high reputation. Intermediate names are bought by good firms, because they can build up the reputation. These names are not bought by bad firms, because there is less value to to be depleted. Good firms find it too expensive to buy a bad name and build up its reputation from scratch.

In this paper, I am able to derive equilibria with sorting of types. I show two types of sorting: some equilibria where competent firms can differentiate themselves by being the only ones buying valuable names, and other equilibria where incompetent firms give themselves away by being the only firms using worthless names.

\section{Conclusion}

In this paper, I raise two questions central to the literature on firm names and reputations. First, I ask whether firm names can be tradeable assets even when changes in name ownership are observable to the consumer. Second, I ask if the market for firm names can act as a sorting device and separate competent firms from incompetent ones.

I consider an infinite horizon economy with generations of firms and consumers interacting in each period. Firms can be competent or incompetent. Firms choose to enter the market under different names which they buy in a competitive market for names. Changes in name ownership are fully observable. There are two kinds of names available. Consumers buy a product from the firm for which they pay upfront. At the time of purchase, consumers only observe the name of the firm. After collecting their payment, firms provide their services. At the end of the period, each firm's name changes according to a fixed transition rule (potentially random) which determines the future of a name based on its original name, realized quality of services, and an idiosyncratic randomization. Before retiring, a firm can sell its name to a new entrant.

With full observability of name changes, I examine the existence of equilibria in which the 
market for names both makes competent firms work hard and sorts firms according to their type. I define a class of equilibria called sorting high-effort equilibria (SHE) where at least one type of firm has a strict incentive to not use one of the two names, and competent firms always work hard. In the main result of the paper, I characterize necessary and sufficient conditions for the existence of such sorting high-effort equilibria (SHE). I show that SHE exist provided the cost of effort is low enough for competent firms.

I also show that the market for firm reputations can act as an effective sorting device that separates competent firms from incompetent ones. Some names can perfectly signal the type of the firm that owns it. Two kinds of sorting may arise in equilibrium. It is possible for competent firms to separate themselves by being the only ones buying the valuable successful names. I call these situations "Trust $S$-Names equilibria". In these equilibria, when consumers see a successful name, they trust it to be a competent firm and pay the corresponding high price. The second type of sorting that arises is termed "Mistrust $N$-Names". Here, incompetent firms give themselves away by being the only firms using the cheap names. Consumers treat cheap names with mistrust and pay them corresponding low wages. Competent firms force this situation to arise by always buying $S$-names before entering the market. 


\section{Appendix}

\subsection{Proof of Proposition 1}

By Lemma 1, we know that in SHE, competent firms playing only $S$-names. This implies that incompetent firms must use both $S$ and $N$-names. The equilibrium conditions are as follows:

Incentive Compatibility for Name Choice

C-firms strictly prefer using $S$-names and working hard to using $N$-names.

$$
\begin{gathered}
-V_{S}+w_{S}-c+\delta(1-\rho) f_{1} V_{S}+\delta \rho f_{2} V_{S}>w_{N}-c+\delta(1-\rho) f_{3} V_{S}+\delta \rho f_{4} V_{S} \\
-V_{S}+w_{S}-c+\delta(1-\rho) f_{1} V_{S}+\delta \rho f_{2} V_{S}>w_{N}+\delta f_{4} V_{S}
\end{gathered}
$$

I-firms are indifferent between $N$-names and $S$-names.

$$
-V_{S}+w_{S}+\delta f_{2} V_{S}=w_{N}+\delta f_{4} V_{S}
$$

Incentives for Competent Firms to Work Hard

$$
c<\delta(1-\rho)\left(f_{1}-f_{2}\right) V_{S}
$$

\section{Equilibrium Determination}

Market Clearing:

$$
\phi+(1-\phi) \mu_{S}=\phi(1-\rho) f_{1}+\phi \rho f_{2}+(1-\phi) \mu_{S} f_{2}+(1-\phi)\left(1-\mu_{S}\right) f_{4}
$$

Wage Determination:

$$
w_{N}=0 \text { and } w_{S}>w_{N}
$$

The effort constraint implies that $f_{1}=1$ and $f_{2}=0$. Further, I claim that $f_{4} \neq f_{2}$. Suppose not, i.e. $f_{4}=f_{2}=0$. Then (16) implies $\mu_{S}=\frac{-\phi \rho}{1-\phi}$ which is not possible. In other words, there would be a shortage of $S$-names and the market would not clear. Hence, we have $f_{4}=1 \neq f_{2}$. This leaves possible only two transition rules with $f_{3}=1$ or $f_{3}=0$. These are precisely the ones depicted in the figure. Consider the first transition rule in the figure (where $f_{3}=1$ ). Conditions (12)-(16) reduce to:

$$
\begin{gathered}
\mu_{S}=\frac{1-\phi-\phi \rho}{2(1-\phi)} \\
w_{S}=\frac{\phi(1-\rho)}{\phi+(1-\phi) \mu_{S}} \\
V_{S}=\frac{w_{S}}{1+\delta}
\end{gathered}
$$




$$
c<\delta(1-\rho) V_{S}
$$

It can easily be seen that if $\phi<\frac{1}{1+\rho}$, these conditions yield a non-empty set of sorting equilibria. Identical conditions arise for the second transition rule.

\subsection{Richer Market with Non-Random Transitions}

Consider a richer market with three names. It turns out that there are only three non-random transition rules which allow sorting high-effort equilibria. Consider the automata below: SHE exist
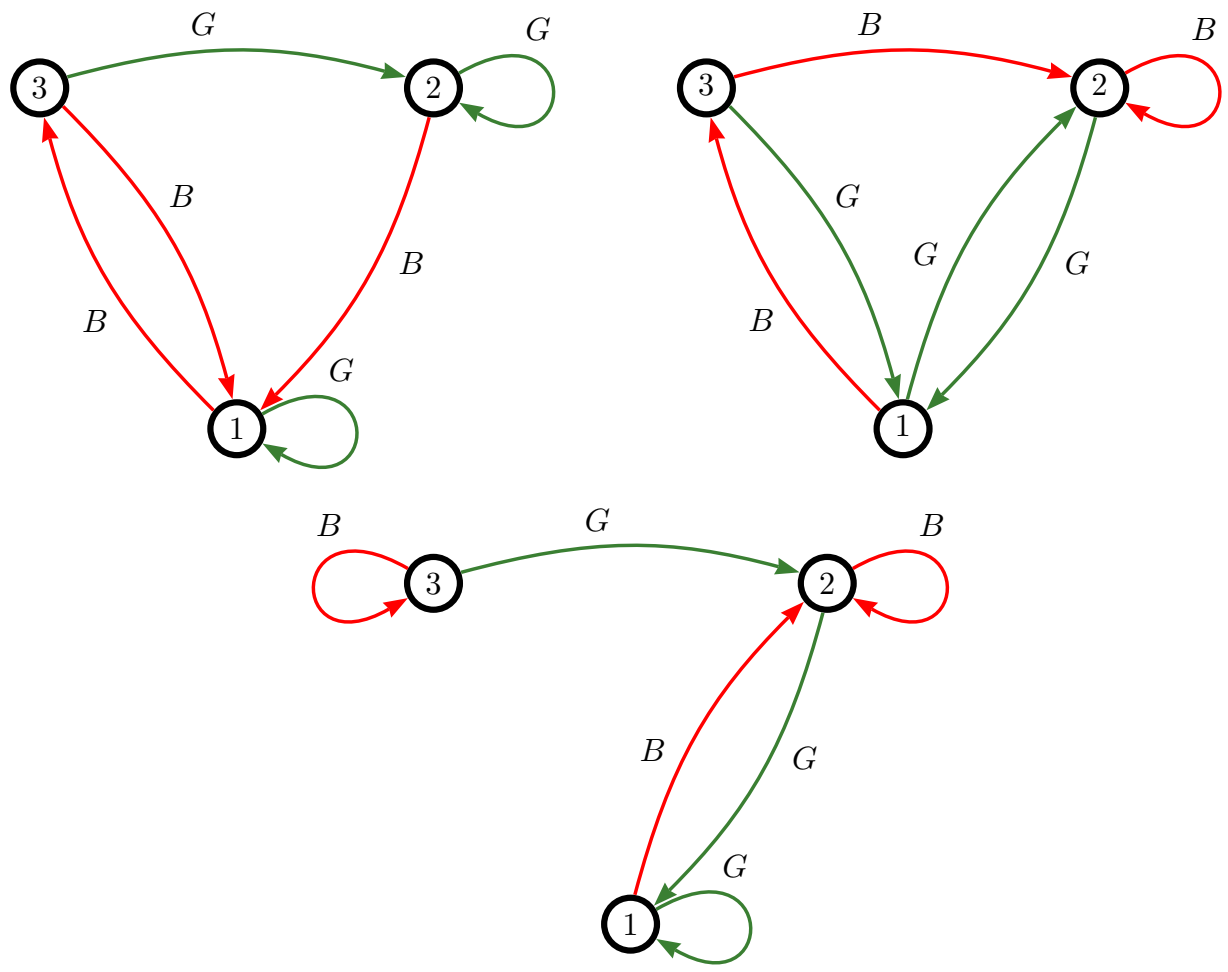

Figure 5: Transitions for SHE in Market with Three States

only under these transition rules. The nature of sorting differs based on the transition rule. With the first two rules, we get "Trust 1-Names" equilibria. In these equilibria, competent firms buy all three names, but only competent firms buy $S_{1}$-names. Incompetent firms buy only $S_{2}$ and $S_{3}$-names. The last transition rule yields "Mistrust 3-Names". Here, competent firms never enter with costless $S_{3}$-names. $I$-firms are the only ones using $S_{3}$ names. 


\subsection{Proof of Proposition 2}

Sufficiency: Fix $\phi, \rho, \delta, c$ with $c<\min \left\{\frac{\delta(1-\rho)^{2}(1-\phi)}{1-\phi+\delta \phi \rho}, \frac{\delta(1-\phi)(1-\rho)^{2}}{\delta(1-\phi)+\phi \rho}\right\}$.

Case $(\mathrm{i}) c<\frac{\delta(1-\rho)^{2}(1-\phi)}{1-\phi+\phi \rho}$

Set the transition probabilities as follows:

$$
\gamma_{1}=\gamma_{3}=1, \gamma_{2}=0, \gamma_{4}<\min \left\{\frac{\phi \rho}{1-\phi}, \frac{\delta(1-\rho)^{2}(1-\phi)-c(1-\phi+\phi \rho)}{\delta(1-\rho)^{2}(1-\phi)+c \delta \phi(1-\phi+\phi \rho)}\right\}
$$

I claim that there exists a "Trust $S$-Names" equilibrium where $C$-firms use $S$-names with probability $\sigma_{S}=\frac{\phi(1-\rho)\left(1-\gamma_{4}\right)+\gamma_{4}}{\phi\left(1+\rho \gamma_{4}\right)}$ and $N$-names with probability $\left(1-\sigma_{S}\right)$. Competent firms always choose to work hard. Equilibrium price $V_{S}=\frac{(1-\rho)(1-\phi)}{1+\delta \rho \gamma_{4}} \frac{1+\rho \gamma_{4}}{\rho+(1-\phi)(1-\rho)\left(1-\gamma_{4}\right)}$.

Notice first that $c<\frac{\delta(1-\rho)^{2}(1-\phi)}{1-\phi+\phi \rho}$ implies that $\gamma_{4}$ is well-defined. Further, since $\gamma_{4}<\frac{\phi \rho}{1-\phi}$, the strategy $\sigma_{S}$ is well-defined. Given the conjectured equilibrium strategies, the wages would be $w_{S}=1-\rho$ and $w_{N}=\frac{(1-\rho)\left[\phi \rho-(1-\phi) \gamma_{4}\right]}{1-\phi+\phi \rho-\gamma_{4}(1-\rho)(1-\phi)}$. The incentive constraints for the $C$-type implies

$$
-V_{S}+w_{S}-c+\delta(1-\rho) V_{S}=w_{N}-c+\delta(1-\rho) V_{S}+\delta \rho \gamma_{4} V_{S} \Longrightarrow V_{S}=\frac{w_{S}-w_{N}}{1+\delta \rho \gamma_{4}}
$$

It is easy to check that the proposed $V_{S}$ satisfies the above. $I$-type's incentive constraints imply

$$
V_{S}>\frac{w_{S}-w_{N}}{1+\delta \gamma_{4}}
$$

The conjectured $V_{S}$ also satisfies this condition. Here, incentive compatibility of the competent type implies incentive compatibility for the incompetent type. The market clearing condition is also satisfied with these equilibrium strategies. Finally for the competent type to exert effort we need to check the following conditions.

$$
c<\delta(1-\rho) V_{S} \quad \text { and } \quad c<\delta(1-\rho)\left(1-\gamma_{4}\right) V_{S}
$$

Clearly, it suffices to show that the second constraint holds. We need the following inequality:

$$
\begin{aligned}
& c<\frac{\delta(1-\rho)^{2}(1-\phi)\left(1-\gamma_{4}\right)\left(1+\rho \gamma_{4}\right)}{\left[1+\delta \rho \gamma_{4}\right]\left[\rho+(1-\phi)(1-\rho)\left(1-\gamma_{4}\right)\right.} \\
& \text { Now, } \quad\left(1+\rho \gamma_{4}\right)\left(1+\delta \phi \gamma_{4}\right)=1+\delta \rho \gamma_{4}+\rho \gamma_{4}(1-\delta)+\delta \phi \gamma_{4}\left(1+\rho \gamma_{4}\right) \\
& \text { So, } \quad\left(1+\rho \gamma_{4}\right)\left(1+\delta \phi \gamma_{4}\right) \geq 1+\delta \rho \gamma_{4} \text {. } \\
& \text { Further, } \quad(1-\phi+\phi \rho)=\rho+(1-\phi)(1-\rho) \geq \rho+(1-\phi)(1-\rho)\left(1-\gamma_{4}\right) \\
& \Longrightarrow \frac{1}{\left(1+\delta \phi \gamma_{4}\right)(1-\phi+\phi \rho)} \leq \frac{1+\rho \gamma_{4}}{\left[\rho+(1-\phi)(1-\rho)\left(1-\gamma_{4}\right)\right]\left[1+\delta \rho \gamma_{4}\right]} \text {. }
\end{aligned}
$$


This implies that

$$
\frac{\delta(1-\rho)^{2}(1-\phi)\left(1-\gamma_{4}\right)}{\left(1+\delta \phi \gamma_{4}\right)(1-\phi+\phi \rho)} \leq \frac{\delta(1-\rho)^{2}(1-\phi)\left(1-\gamma_{4}\right)\left[1+\rho \gamma_{4}\right]}{\left[\rho+(1-\phi)(1-\rho)\left(1-\gamma_{4}\right)\right]\left[1+\delta \rho \gamma_{4}\right]}=\delta(1-\rho)\left(1-\gamma_{4}\right) V_{S}
$$

But recall that by definition of $\gamma_{4}$,

$$
\begin{gathered}
\gamma_{4}<\frac{\delta(1-\rho)^{2}(1-\phi)-c(1-\phi+\phi \rho)}{\delta(1-\rho)^{2}(1-\phi)+c \delta \phi(1-\phi+\phi \rho)} \\
\Longrightarrow c<\frac{\delta(1-\rho)^{2}(1-\phi)\left(1-\gamma_{4}\right)}{\left(1+\delta \phi \gamma_{4}\right)(1-\phi+\phi \rho)}
\end{gathered}
$$

So, by the above inequality, $c<\delta(1-\rho)\left(1-\gamma_{4}\right) V_{S}$.

Case(ii) $\frac{\delta(1-\rho)^{2}(1-\phi)}{1-\phi+\phi \rho} \leq c<\min \left\{\frac{\delta(1-\rho)^{2}(1-\phi}{1-\phi+\delta \phi \rho}, \frac{\delta(1-\phi)(1-\rho)^{2}}{\delta(1-\phi)+\phi \rho}\right\}$

First consider cases where $\phi \rho<1-\phi$. This implies that $\frac{\delta(1-\rho)^{2}(1-\phi)}{1-\phi+\phi \rho} \leq c<\frac{\delta(1-\rho)^{2}(1-\phi)}{1-\phi+\delta \phi \rho}$. Fix the following transition probabilities:

$$
\gamma_{1}=\gamma_{3}=1, \gamma_{2}=0, \gamma_{4} \in\left(\frac{\phi \rho}{1-\phi}, \frac{\delta \phi(1-\rho)^{2}\left(1+\frac{\phi \rho}{1-\phi}\right)-c \phi(1-\rho)\left(1+\frac{\delta \phi \rho}{1-\phi}\right)}{c\left(1+\frac{\delta \phi \rho}{1-\phi}\right)}\right)
$$

I claim that that there exists a "Mistrust $N$-Names" equilibrium where, incompetent firms use $S$-names with probability $\mu_{S}=\frac{(1-\phi) \gamma_{4}-\phi \rho}{(1-\phi)\left(1+\gamma_{4}\right)}$ and $N$-names with $1-\mu_{S}$. Competent firms choose to work hard on the equilibrium path. Equilibrium price $V_{S}=\frac{\phi(1-\rho)\left(1+\gamma_{4}\right)}{\left[1+\delta \gamma_{4}\right]\left[\gamma_{4}+\phi(1-\rho)\right]}$.

First, we check that the transition probabilities chosen are well-defined.

$$
\begin{gathered}
c<\frac{\delta(1-\rho)^{2}(1-\phi)}{1-\phi+\delta \phi \rho} \\
\Longrightarrow \phi \delta(1-\rho)^{2}(1-\phi)-\phi c(1-\phi+\delta \phi \rho)>0 \\
\Longrightarrow \phi \delta(1-\rho)^{2}(1-\phi+\delta \phi \rho)-(1-\rho) \phi c(1-\phi+\delta \phi \rho)>0 \\
\Longrightarrow\left(1+\frac{\phi \rho}{1-\phi}\right) \phi \delta(1-\rho)^{2}-\left(1+\frac{\delta \phi \rho}{1-\phi}\right)(1-\rho) \phi c>0
\end{gathered}
$$

So the upper bound for $\gamma_{4}$ is well-defined. Further,

$$
c<\frac{\delta(1-\rho)^{2}(1-\phi)}{1-\phi+\delta \phi \rho} \Longrightarrow \frac{\phi \rho}{1-\phi}<\frac{\delta \phi(1-\rho)^{2}\left(1+\frac{\phi \rho}{1-\phi}\right)-c \phi(1-\rho)\left(1+\frac{\delta \phi \rho}{1-\phi}\right)}{c\left(1+\frac{\delta \phi \rho}{1-\phi}\right)} .
$$

So, the interval from which $\gamma_{4}$ is chosen is well-defined. Given the conjectured strategies the wages are $w_{N}=0$ and $w_{S}=\frac{\phi(1-\rho)\left(1+\gamma_{4}\right)}{\gamma_{4}+\phi(1-\rho)}$. For $I$-firms to be indifferent between $S$ and $N$-names, we need:

$$
V_{S}=\frac{w_{S}-w_{N}}{1+\delta \gamma_{4}}
$$


We can check that $V_{S}$ satisfies this condition. Hence, $C$-firms strictly prefer $S$-names to $N$-names. Since $\gamma_{4}>\frac{\phi \rho}{1-\phi}, \mu_{S}$ is well-defined, and satisfies the market clearing conditions. It only remains to check that competent firms have an incentive to work hard on the equilibrium path, i.e. $c<$ $\delta(1-\rho) V_{S}$. To prove this, define a function

$$
\psi(x)=\frac{\delta \phi(1-\rho)^{2}}{\gamma_{4}+\phi(1-\rho)} \frac{1+x}{1+\delta x}
$$

Notice that this function is strictly increasing in $x$. Recall that

$$
\gamma_{4}<\frac{\delta \phi(1-\rho)^{2}\left(1+\frac{\phi \rho}{1-\phi}\right)-c \phi(1-\rho)\left(1+\frac{\delta \phi \rho}{1-\phi}\right)}{c\left(1+\frac{\delta \phi \rho}{1-\phi}\right)} \Longrightarrow c<\frac{\delta \phi(1-\rho)^{2}\left(1+\frac{\phi \rho}{1-\phi}\right)}{\left(1+\frac{\delta \phi \rho}{1-\phi}\right)\left(\gamma_{4}+\phi(1-\rho)\right.}=\psi\left(\frac{\phi \rho}{1-\phi}\right) \text {. }
$$

By the monotonicity of $\psi($.$) , if \gamma_{4}>\frac{\phi \rho}{1-\phi}$ then $c<\psi\left(\gamma_{4}\right)$. So, for $\gamma$ in the specified range,

$$
c<\psi\left(\gamma_{4}\right)=\frac{\delta \phi(1-\rho)^{2}\left(1+\gamma_{4}\right)}{\left(\gamma_{4}+\phi(1-\rho)\right)\left(1+\delta \gamma_{4}\right)}=\delta(1-\rho) V_{S} .
$$

This proves that we have found a "Mistrust $N$-Names" equilibrium.

Using a very similar argument as above, we can show that "Mistrust $N$-Names Equilibria" exist also in the case when $\phi \rho>1-\phi$.

Necessity: Propositions $4 \& 5$ characterize the types of SHE that exist. We can use these characterizations to show that a necessary condition for SHE to exist is that the cost of hard work is less than the upper bound.

Consider "Trust $S$-names" equilibria. Using the characterization in Proposition 4, we derive a maximal cost of effort for which it is possible to find transition rules to support SHE. Finding such an upper bound reduces to solving the following constrained maximization problem.

$$
\begin{gathered}
\max _{\gamma_{1}, \gamma_{2}, \gamma_{3}, \gamma_{4}} \frac{\delta(1-\rho)^{2}(1-\phi)\left(\gamma_{3}-\gamma_{4}\right)}{1+\delta(1-\rho)\left(\gamma_{3}-\gamma_{1}\right)+\delta \rho\left(\gamma_{4}-\gamma_{2}\right)} \frac{1+(1-\rho)\left(\gamma_{3}-\gamma_{1}\right)+\rho\left(\gamma_{4}-\gamma_{2}\right)}{1-(1-\rho) \gamma_{1}-\rho \gamma_{2}+(1-\phi)(1-\rho)\left(\gamma_{3}-\gamma_{4}\right)} \\
\text { subject to } \quad \gamma_{1}-\gamma_{2}-\gamma_{3}+\gamma_{4}>0 \\
-\gamma_{4}(1-\phi)+\phi\left(1-(1-\rho) \gamma_{1}-\rho \gamma_{2}\right)>0 \\
\gamma_{1}, \gamma_{2}, \gamma_{3}, \gamma_{4} \geq 0 \\
\gamma_{1}, \gamma_{2}, \gamma_{3}, \gamma_{4} \leq 1
\end{gathered}
$$

The constraints are linear and so the constraint qualification condition holds. Further it can be verified that constraints (26) and (27) bind. So plugging back $\gamma_{4}$ and $\gamma_{3}$ and solving the reduced problem, we find that the objective function is maximized at

$\gamma_{1}=\gamma_{3}=1 \quad \gamma_{2}=\gamma_{4}=\frac{\phi \rho}{1-\phi+\phi \rho} \quad$ and the maximal value is $\quad c_{\max }^{1}=\frac{\delta(1-\phi)(1-\rho)^{2}}{1-\phi+\phi \rho}$ 
Next, consider "Mistrust $N$-names" equilibria. We will examine two cases:

Case A: Cost of hard work is low enough that it is sequentially rational for a $C$-firm to work hard on and off the equilibrium path. (i.e., $c<\min \left\{\delta(1-\rho)\left(\gamma_{3}-\gamma_{4}\right) V_{S}, \delta(1-\rho)\left(\gamma_{1}-\gamma_{2}\right) V_{S}\right\}$.)

Case B: Cost of work is low enough to sustain hard work only on the equilibrium path.

For equilibria under Case (A), the conditions of Proposition 5 imply

$c<\delta(1-\rho)\left(\gamma_{3}-\gamma_{4}\right) \frac{\phi(1-\rho)}{\left[\phi+(1-\phi) \mu_{S}\right]\left[1+\delta\left(\gamma_{4}-\gamma_{2}\right)\right]}$. To find the maximal value of the RHS of this constraint, we solve the following problem:

$$
\begin{gathered}
\max _{\gamma_{1}, \gamma_{2}, \gamma_{3}, \gamma_{4}} \frac{\delta(1-\rho)^{2} \phi\left(\gamma_{3}-\gamma_{4}\right)}{1+\delta\left(\gamma_{4}-\gamma_{2}\right)} \frac{1+\gamma_{4}-\gamma_{2}}{\phi(1-\rho)\left(\gamma_{1}-\gamma_{2}\right)+\gamma_{4}} \\
\text { subject to } \gamma_{1}-\gamma_{2}-\gamma_{3}+\gamma_{4}>0 \\
\gamma_{4}(1-\phi)-\phi\left(1-(1-\rho) \gamma_{1}-\rho \gamma_{2}\right)>0 \\
1-\gamma_{2}-\phi(1-\rho)\left(\gamma_{1}-\gamma_{2}\right)>0 \\
\gamma_{1}, \gamma_{2}, \gamma_{3}, \gamma_{4} \geq 0 \\
\gamma_{1}, \gamma_{2}, \gamma_{3}, \gamma_{4} \leq 1
\end{gathered}
$$

Here constraints (30) and (31) bind. Solving the reduced problem we find the objective function is maximized at

$\gamma_{1}=\gamma_{3}=1 \quad \gamma_{2}=\gamma_{4}=\frac{\phi \rho}{1-\phi+\phi \rho} \quad$ and the maximal value of $c$ is $c_{\max }^{2}=\frac{\delta(1-\phi)(1-\rho)^{2}}{1-\phi+\phi \rho}$.

Note that in the two maximization problems, the maximum and the maximizers are exactly the same. For the equilibria covered by Case (B), conditions of Proposition 5 imply

$\delta(1-\rho)\left(\gamma_{3}-\gamma_{4}\right) \frac{\phi(1-\rho)}{\left[\phi+(1-\phi) \mu_{S}\right]\left[1+\delta\left(\gamma_{4}-\gamma_{2}\right)\right]} \leq c<\delta(1-\rho)\left(\gamma_{1}-\gamma_{2}\right) \frac{\phi(1-\rho)}{\left[\phi+(1-\phi) \mu_{S}\right]\left[1+\delta\left(\gamma_{4}-\gamma_{2}\right)\right]}$

Again, we solve the constrained maximization problem given by

$$
\max _{\gamma_{1}, \gamma_{2}, \gamma_{4}} \frac{\delta(1-\rho)^{2} \phi\left(\gamma_{1}-\gamma_{2}\right)}{1+\delta\left(\gamma_{4}-\gamma_{2}\right)} \frac{1+\left(\gamma_{4}-\gamma_{2}\right)}{\gamma_{4}+\phi(1-\rho)\left(\gamma_{1}-\gamma_{2}\right)}
$$

subject to

$$
\begin{gathered}
\gamma_{4}(1-\phi)-\phi\left(1-(1-\rho) \gamma_{1}-\rho \gamma_{2}\right)>0 \\
1-\gamma_{2}-\phi(1-\rho)\left(\gamma_{1}-\gamma_{2}\right)>0 \\
\gamma_{1}, \gamma_{2}, \gamma_{4} \geq 0 \\
\gamma_{1}, \gamma_{2}, \gamma_{4} \leq 1
\end{gathered}
$$


It can be verified that:

1. For $\phi, \rho$ such that $\phi<\frac{1}{1+\rho}$, the objective function is maximized at

$$
\gamma_{1}=1 \quad \gamma_{2}=0 \quad \gamma_{4}=\frac{\phi \rho}{1-\phi} \quad \text { and the maximal value of } c \text { is } c_{\max }^{3}=\frac{\delta(1-\phi)(1-\rho)^{2}}{1-\phi+\delta \phi \rho}
$$

2. For $\phi, \rho$ such that $\phi>\frac{1}{1+\rho}$, the objective function gets maximized at

$$
\gamma_{1}=1 \quad \gamma_{2}=1-\frac{1-\phi}{\phi \rho} \quad \gamma_{4}=1 \quad \text { and the maximal value of } c \text { is } c_{\max }^{4}=\frac{\delta(1-\phi)(1-\rho)^{2}}{\delta(1-\phi)+\phi \rho}
$$

Inspecting the upper bounds we see that a necessary condition for sorting equilibria to exist is:

$$
c<\min \left\{\frac{\delta(1-\phi)(1-\rho)^{2}}{1-\phi+\delta \phi \rho}, \frac{\delta(1-\phi)(1-\rho)^{2}}{\delta(1-\phi)+\phi \rho}\right\} .
$$

\subsection{Proof of Proposition 4}

Consider "Trust $S$-names" equilibria. The equilbrium conditions are as follows:

\section{Incentive Compatibility for Name Choice}

$C$-firms must be indifferent between $N$ and $S$-names.

$$
\begin{gathered}
-V_{S}+w_{S}-c+\delta(1-\rho) \gamma_{1} V_{S}+\delta \rho \gamma_{2} V_{S}=w_{N}-c+\delta(1-\rho) \gamma_{3} V_{S}+\delta \rho \gamma_{4} V_{S} \\
\text { So, } \quad V_{S}=\frac{w_{S}-w_{N}}{1+\delta(1-\rho)\left(\gamma_{3}-\gamma_{1}\right)+\delta \rho\left(\gamma_{4}-\gamma_{2}\right)}
\end{gathered}
$$

$I$ firms must strictly prefer $N$-names to $S$-names.

$$
w_{N}+\delta \gamma_{4} V_{S}>-V_{S}+w_{S}+\delta \gamma_{2} V_{S} \Longrightarrow V_{S}\left[1+\delta\left(\gamma_{4}-\gamma_{2}\right)\right]>w_{S}-w_{N}
$$

\section{Incentives for Competent Firms to Work Hard}

$$
\begin{aligned}
& c<\delta(1-\rho) V_{S}\left(\gamma_{1}-\gamma_{2}\right) \\
& c<\delta(1-\rho) V_{S}\left(\gamma_{3}-\gamma_{4}\right)
\end{aligned}
$$

\section{Equilibrium Determination}

Market Clearing $\quad \phi \sigma_{S}=\phi \sigma_{S}(1-\rho) \gamma_{1}+\phi \sigma_{S} \rho \gamma_{2}+\phi\left(1-\sigma_{S}\right)(1-\rho) \gamma_{3}+\phi\left(1-\sigma_{S}\right) \rho \gamma_{4}+(1-\phi) \gamma_{4}$

$$
\text { So, } \quad \sigma_{S}=\frac{\phi(1-\rho)\left(\gamma_{3}-\gamma_{4}\right)+\gamma_{4}}{\phi(1-\rho)\left(\gamma_{3}-\gamma_{1}\right)+\phi \rho\left(\gamma_{4}-\gamma_{2}\right)+\phi}
$$

Wage Determination $\quad w_{S}=1-\rho>w_{N}=\frac{\phi\left(1-\sigma_{S}\right)(1-\rho)}{\phi\left(1-\sigma_{S}\right)+1-\phi}$. 


$$
\begin{gathered}
V_{S}>0 \\
\sigma_{S} \in(0,1)
\end{gathered}
$$

The incentive constraints of $C$-firms and $I$-firms together imply that (1) holds. The effort constraint for a $C$-firm with an $S$-name (41) is equivalent to condition (3). Consider the market clearing condition (43). Since the effort constraint (42) implies that $\gamma_{3}>\gamma_{4}$, we know that the numerator of $(43)$ is positive. So, $\sigma_{S} \in(0,1)$, implies that the denominator in (43) must be greater than the denominator. This implies (2) holds.

Conversely, assume that conditions (1) through (3) in the proposition are satisfied. I claim the following "Trust $S$-names" high-effort equilibrium exists. Competent firms buy both $S$ and $N$-names. They buy $S$-names with probability $\sigma_{S}=\frac{\phi(1-\rho)\left(\gamma_{3}-\gamma_{4}\right)+\gamma_{4}}{\phi(1-\rho)\left(\gamma_{3}-\gamma_{1}\right)+\phi \rho\left(\gamma_{4}-\gamma_{2}\right)+\phi}$. Incompetent firms buy only $N$-names. Consequently,wages are $w_{S}=1-\rho$ and $w_{N}=\frac{\phi\left(1-\sigma_{S}\right)(1-\rho)}{\phi\left(1-\sigma_{S}\right)+1-\phi}$. S-names trade at a price $V_{S}=\frac{w_{S}-w_{N}}{1+\delta\left(\gamma_{4}-\gamma_{2}\right)}$.

For an equilibrium, we need to check (39) to (45). We know $V_{S} \geq 0$. By definition, (39) and (43) hold and (3) is equivalent to (42). Since $c>0,(1)$ and (3) imply (41) holds. (1) also implies (40) holds. Finally, (1) and (3) imply that the numerator in (43) is positive. Condition (2) implies that the numerator is strictly lesser than the denominator; so (45) holds.

\subsection{Proof of Proposition 5}

The proof is similar to that of Proposition 4. Suppose that for given $\phi, \rho, \gamma_{1}, \gamma_{2}, \gamma_{3}, \gamma_{4}, \delta$ and $c$, there exists a "Mistrust $N$-names" equilibrium. The equilibrium conditions are as follows:

\section{Incentive Compatibility for Name Choice}

$C$-firms strictly prefer an $S$-name to an $N$-name.

$$
\begin{gathered}
-V_{S}+w_{S}-c+\delta(1-\rho) \gamma_{1} V_{S}+\delta \rho \gamma_{2} V_{S}>w_{N}-c+\delta(1-\rho) \gamma_{3} V_{S}+\delta \rho \gamma_{4} V_{S} \\
\qquad V_{S}<\frac{w_{S}-w_{N}}{1+\delta(1-\rho)\left(\gamma_{3}-\gamma_{1}\right)+\delta \rho\left(\gamma_{4}-\gamma_{2}\right)} \\
\text { Further, }-V_{S}+w_{S}-c+\delta(1-\rho) \gamma_{1} V_{S}+\delta \rho \gamma_{2} V_{S}>w_{N}+\delta \gamma_{4} V_{S} \\
\text { So, } \quad V_{S}\left(1+\delta \gamma_{4}-\delta(1-\rho) \gamma_{1}-\delta \rho \gamma_{2}\right)<w_{S}-w_{N}-c
\end{gathered}
$$

$I$-firms are indifferent between $N$-names and $S$-names.

$$
V_{S}\left[1+\delta\left(\gamma_{4}-\gamma_{2}\right)\right]=w_{S}-w_{N}
$$




\section{Incentives for Competent Firms to Work Hard}

$$
c<\delta(1-\rho) V_{S}\left(\gamma_{1}-\gamma_{2}\right)
$$

\section{Equilibrium Determination}

$$
\begin{gathered}
\text { Market Clearing } \Longrightarrow \mu_{S}=\frac{\phi(1-\rho) \gamma_{1}+\phi \rho \gamma_{2}+(1-\phi) \gamma_{4}-\phi}{(1-\phi)\left(1+\gamma_{4}-\gamma_{2}\right)} \\
\text { Wage Determination } \quad w_{N}=0<w_{S}=\frac{\phi(1-\rho)}{\phi+(1-\phi) \mu_{S}} . \\
\qquad V_{S}>0 \text { and } \\
\mu_{S} \in(0,1)
\end{gathered}
$$

Clearly, we need $\mu_{S} \in(0,1)$. This implies that the second inequality in Conditions 1 and 2 hold. (49) is equivalent to Condition 3. Finally, the incentive constraints (46) and (48) together imply that the first inequality in Condition 1 holds. This proves the necessary conditions.

Conversely, suppose that there for given $\phi, \rho, \gamma_{1}, \gamma_{2}, \gamma_{3}, \gamma_{4}, \delta$ and $c$, the conditions of the proposition are satisfied. I claim that there exists a "Mistrust $N$-names" equilibrium in which incompetent firms buy $S$-names with probability $\mu_{S}$ given by (50) and where the price of an $S$-name, $V_{S}$ is given by (48). To verify that this is an equilibrium, we need to check for conditions (46) through (52). Conditions (48) through (51) are trivially satisfied.

$$
\begin{gathered}
\gamma_{3}-\gamma_{1}<\gamma_{4}-\gamma_{2} \Longrightarrow 1+\delta(1-\rho)\left(\gamma_{3}-\gamma_{1}\right)+\delta \rho\left(\gamma_{4}-\gamma_{2}\right)<1+\delta\left(\gamma_{4}-\gamma_{2}\right) \\
\Longrightarrow V_{S}\left[1+\delta(1-\rho)\left(\gamma_{3}-\gamma_{1}\right)+\delta \rho\left(\gamma_{4}-\gamma_{2}\right)\right]<V_{S}\left[1+\delta\left(\gamma_{4}-\gamma_{2}\right)\right] \\
\Longrightarrow(46) \text { is satisfied. }
\end{gathered}
$$

(A4) and (46) imply that the other IC of the $C$-type (47) is also satisfied. Condition (3) and (49) are equivalent. Conditions (1) and (2) ensure that (52) holds. It remains to be shown that the second incentive constraint for the $C$-type (47) also holds. Consider two cases:

Case(i) $c<\delta(1-\rho)\left(\gamma_{3}-\gamma_{4}\right) \frac{\phi(1-\rho)}{\left[\phi+(1-\phi) \mu_{S}\right]\left[1+\delta\left(\gamma_{4}-\gamma_{2}\right)\right]}: \quad c$ is low enough for $C$-firms to work hard in every state. (47) is implied by the first IC constraint of the $C$-type and we are done.

Case (ii) $c \geq \delta(1-\rho)\left(\gamma_{3}-\gamma_{4}\right) \frac{\phi(1-\rho)}{\left[\phi+(1-\phi) \mu_{S}\right]\left[1+\delta\left(\gamma_{4}-\gamma_{2}\right)\right]}$ : Here, a $C$-firm works hard only if it buys an $S$-name. Then, the IC of $I$-type and (3) imply (47) holds. This proves sufficiency. 


\section{References}

[1] Hakenes, Hendrik, and Martin Peitz. 2007. "Observable reputation trading." International Economic Review, 48(2):693-730.

[2] Kreps, David. 1990 "Corporate culture and economic theory." In Perspectives on Positive Political Economy, ed. J. Alt and K. Shepsle, 90-143, 1990.

[3] Mailath, George J. and Larry Samuelson. 2001. "Who wants a good reputation?" Review of Economic Studies, 68(2):415-41.

[4] Mailath, George J., and Larry Samuelson. 2006. Repeated Games and Reputations. Oxford University Press

[5] Tadelis, Steven. 1999. "What's in a name? reputation as a tradeable asset." American Economic Review, 89(3):548-563.

[6] Tadelis, Steven. 2002 "The market for reputations as an incentive mechanism." Journal of Political Economy, 110(4):854-882.

[7] Tadelis, Steven. 2003. "Firm reputation with hidden information." Economic Theory, 21(2):635-651. 